\title{
Feasibility of hydrogen fuel cell technology for railway intercity services: a case study for the Piedmont in North Carolina
}

\author{
Orwell Madovi ${ }^{1}$ (D) Andreas Hoffrichter ${ }^{2} \cdot$ Nick Little $^{2} \cdot$ Shanelle N. Foster $^{1}$. \\ Raphael Isaac $^{2}$
}

Received: 14 February 2021 / Revised: 14 July 2021/Accepted: 15 July 2021 / Published online: 31 July 2021

(C) The Author(s) 2021

\begin{abstract}
Diesel fuel combustion results in exhaust containing air pollutants and greenhouse gas emissions. Many railway vehicles use diesel fuel as their energy source. Exhaust emissions, as well as concerns about economical, alternative power supply, have driven efforts to move to hydrogen motive power. Hydrogen fuel cell technology applied to railways offers the opportunity to eliminate harmful exhaust emissions and the potential for a low- or zero-emission energy supply chain. Currently, only multiple-unit trains with hydrail technology operate commercially. Development of an Integrated Hybrid Train Simulator for intercity railway is presented. The proposed tool incorporates the effect of powertrain components during the wheel-to-tank process. Compared to its predecessors, the proposed reconfigurable tool provides high fidelity with medium requirements and minimum computation time. Single train simulation and the federal government's Greenhouse gases, Regulated Emissions, and Energy use in Transportation $\left(\right.$ GREET $\left.^{\circledR}\right)$ model are used in combination to evaluate the feasibility of various train and powertrain configurations. The Piedmont intercity service operating in North Carolina is used as a case study. The study includes six train configurations and powertrain options as well as nine hydrogen supply options in addition to the diesel supply. The results show that a hydrail option
\end{abstract}

Orwell Madovi

madovior@msu.edu

1 Department of Electrical and Computer Engineering, Michigan State University, 428 South Shaw Lane, Room 2120, East Lansing, MI 48824, USA

2 Center for Railway Research \& Education, Broad College of Business, Michigan State University, 3535 Forest Road, Room C-36, Lansing, MI 48910, USA is not only feasible, but a low- or zero-carbon hydrogen supply chain could be possible.

Keywords Hydrail - Life cycle assessment - Criteria pollutants · Well-to-wheel - Single train simulation · Modeling

\section{Introduction}

In the USA, modal shift from road to rail reduces energy consumption and emissions from the transportation sector even if current diesel technology is employed [1]. However, utilization of hydrocarbons by humans and the subsequent release of greenhouse gases (GHGs) has been linked to climate change [2]. Efforts to introduce low- or zero-emission motive power options will increase the rail advantage and are necessary for the mode to remain environmentally competitive given the emergence of lower emission options in the road sector.

In this work, two existing simulation approaches are combined to develop an integrated simulation tool for evaluation of zero-emission options. The proposed reconfigurable tool provides high fidelity with minimum computation time while addressing challenges of current simulators. The proposed tool is applied to the Piedmont corridor route in the USA to assess feasibility of hydrail.

Currently, most railway vehicles use electricity for propulsion either supplied through wayside electrification infrastructure or through on-board diesel-generator sets [3]. On-board power generation is typically achieved with a diesel engine connected to an electricity generator. The resulting electricity is subsequently used to operate traction motors. This powertrain is diesel-electric, though often 
simply referred to as diesel. A diesel-electric powertrain with a three-phase generator and three-phase traction motors represents a typical modern arrangement for passenger and freight motive power vehicles in North America. Rail energy consumption from diesel-electric motive power dominates in the USA, while the remainder is provided by electricity from wayside infrastructure [4].

Wayside electrification eliminates emissions at the point-of-use but requires extensive infrastructure that is associated with substantial capital expenditure. Additionally, the overall environmental performance is dependent on the source utilized for electricity generation. Lower emissions, compared to diesel, can be achieved with renewable sources. However, an increase is also possible if coal is the primary electricity generation source.

Efforts to reduce energy consumption and emissions must also consider braking phases. During braking phases, energy must be dissipated. All trains have a mechanical braking system, where brake pads or shoes are applied to the wheel or a brake disk is controlled through pneumatic connections along the train with air provided by the locomotive. An alternative method is the utilization of the traction motors as generators, where the resulting electricity is converted to heat in resistor grids. Known as dynamic braking, this method is extensively employed in the USA. With the appropriate technology, most of the generated electricity from dynamic braking can be stored on-board the train, an option known as regenerative braking. On-board energy storage systems (ESS) enable the capture of energy resulting from dynamic braking, particularly on downhill segments and in deceleration phases $[5,6]$. For example, when approaching station stops, such energy can be stored and then deployed in the next acceleration phase, decreasing the primary fuel requirement.

The need to satisfy increasingly tighter standards for criteria air pollutants set by the U.S. Environmental Protection Agency and efforts by individual states, such as California, to require full zero-emission applications in the next two decades, has led to investigation of technologies beyond the conventional combustion reciprocating engine [7]. A combination of options, including after-treatment systems, increased use of biofuel, and plug-in hybrid powertrains, are likely to result in significant emission reduction but will not lead to a zero-emission option. Hydrogen utilization in fuel cells, on the other hand, results in no harmful emissions and can be completely carbon free if renewable hydrogen production is used. However, the feasibility of converting railway motive power to this zeroemission option must be thoroughly evaluated.

Simulation tools are required to evaluate the feasibility of hydrogen technology applied to railway vehicles (hydrail) for various railway services, including intercity service. Currently, the primary tool utilized to evaluate train performance is single train simulation, such as Rail Traffic Controller, RailSys, or the Single Train Simulator (STS), developed by the University of Birmingham [8-10]. However, these tools do not adequately represent the powertrain, especially if new powertrains such as hybrids or hydrogen fuel cells have to be modeled. Evaluation of changes in energy due to system changes is not feasible with the STS tool.

The WARwick Powertrain Simulation Tool for ARchitectures (WARPSTAR) [11, 12], developed by the University of Warwick, is a modeling software that focuses on the evaluation of powertrains, including novel options such as hybrids and hydrogen fuel cell systems for light duty vehicles. On the other hand, the WARPSTAR tool incorporates details of system components to improve model fidelity; however, it cannot evaluate the power demand for routes nor the power demand at the wheel level for railway vehicles.

In this work, an Integrated Hybrid Train Simulator (IHyTS) is adopted in order to facilitate accurate analysis of more complex railway vehicle architectures and assessment of their impacts on emissions and energy consumption. Additionally, the well-established Greenhouse gases, Regulated Emissions, and Energy use in Transportation $\left(\mathrm{GREET}^{\circledR}\right)$ model are used for the well-to-pump part of the analysis while emission data from the GREET model is incorporated into the outputs of the developed train simulator for the pump-to-wheel part. (See Sect. 3.2 for further discussion of fuel life cycle terminology) [13]. The feasibility analysis method presented includes route and train information, as well as efficiency maps for all major powertrain components.

Although the proposed IHyTS can be used to evaluate feasibility of many powertrain configurations, here hydrogen fuel cell is evaluated. The equipment used to provide the intercity Piedmont service in North Carolina is owned by the North Carolina Department of Transportation (NCDOT) and used as a case study to evaluate the efficacy of the method. This case study explores six configurations, including hydrogen fuel cell, diesel hybrids, and their respective plug-in options in order to evaluate feasibility given space requirements, capital cost reduction opportunities, and changes, particularly reductions in energy consumption and total emissions outputs.

\section{Hydrogen considerations}

Considering volumetric and gravimetric energy density of various fuels and storage devices depicted in Fig. 1, liquid hydrocarbon fuels have the highest energy density, 


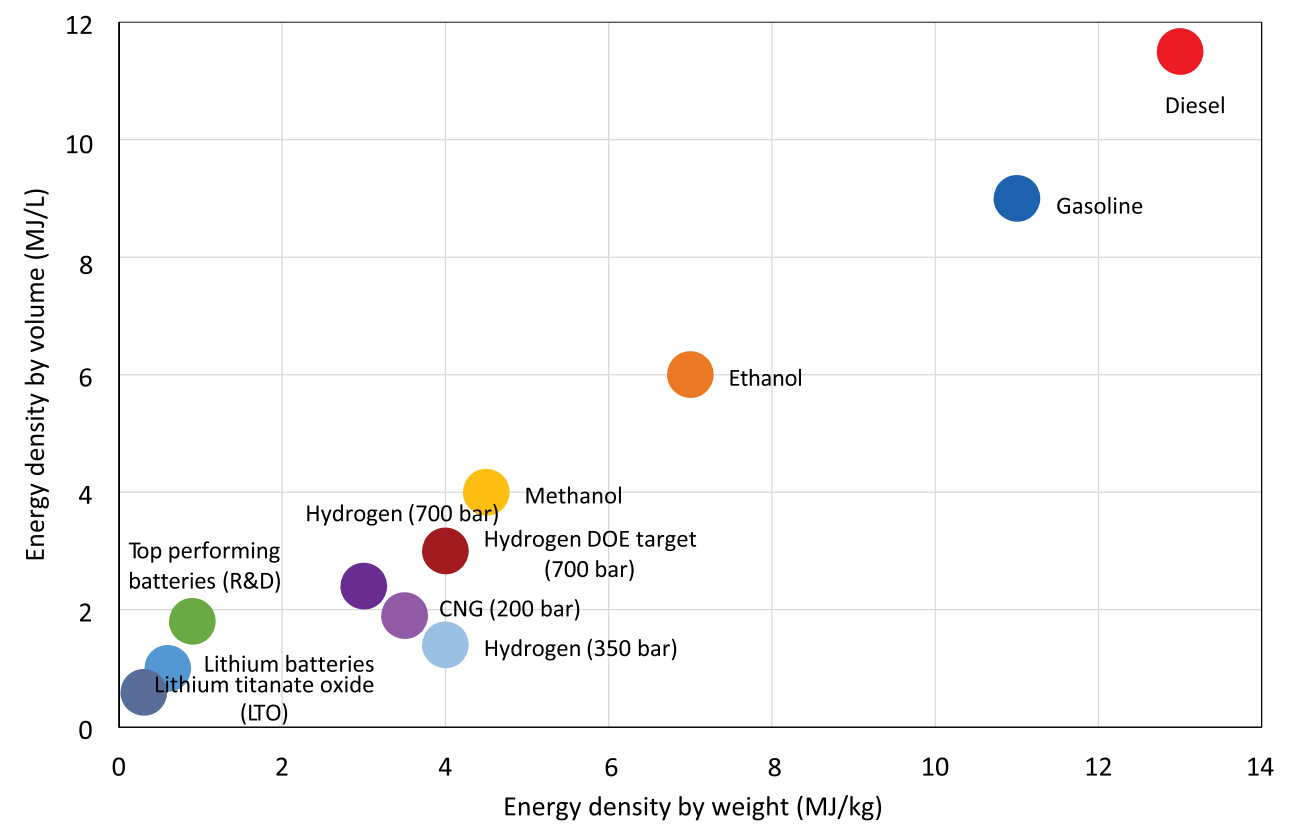

Fig. 1 Energy density of various fuels and energy carriers including tank system weight and volume and accounting for typical powertrain efficiencies [14-16]

therefore requiring the least amount of space and are the lightest of all options. Batteries are at the opposite end with a relatively low energy density by mass and volume, thus being relatively heavy and requiring a significant amount of space in a typical rail application [14-16]. Hydrogen has the highest energy density by mass of any element at $\sim 120 \mathrm{MJ} / \mathrm{kg}$ low heating value ( $142 \mathrm{MJ} / \mathrm{kg}$ high heating value), but very low energy density by volume requiring compression at high pressures, liquefication at low temperatures or other storage mechanisms such as metal hydrides. For vehicle applications including railways, hydrogen is typically stored as a compressed gas at 350 or 700 bar which requires design changes to existing vehicles, nevertheless hydrogen powered trains are in commercial operation and development [17]. Hydrogen has a lower energy density than hydrocarbons, but higher than batteries. However, from a gravimetric perspective, if mass of the diesel-generator-set is considered, total weight of the powertrain between the diesel and hydrogen fuel cell option is similar. The various feedstocks and associated production methods have different impacts on hydrogen cost and environmental performance. Selection of appropriate hydrogen production pathways and sourcing depends on objectives, availability, and the price of hydrogen; trade-offs will likely be required.

\subsection{Hydrogen production}

Hydrogen can be produced from many diverse sources, including algae, natural gas, oil, wood, water and alcohol, to name a few [18]. Methods that use photosynthesis can be used to produce hydrogen from algae. Alcohols like ethanol and methanol derive from gas biomass. They are rich in hydrogen and thus can be reformed to hydrogen. Pyrolysis is used to obtain the hydrogen from biomass. Water electrolysis can also be used to extract hydrogen molecules from water. Electrolysis is attractive since electricity from renewable power sources or nuclear power stations could be used for hydrogen generation, avoiding emissions from production with the possibility of an entirely renewable energy supply chain. The use of gasification technology can also produce hydrogen from coal. Many have estimated the cost of producing hydrogen from coal, but the reported costs vary considerably. The variations in costs are due to different process configurations and process conditions as well as to different assumptions for economic and financial parameters [19].

Currently, the most common hydrogen feedstock in the USA is natural gas [20]. Water and natural gas are reformed to create hydrogen and $\mathrm{CO}_{2}$; this method is known as steam methane reforming (SMR). This study 
considers three methods for hydrogen production: (1) SMR, (2) electrolysis, and (3) biomass. For electrolysis, this work considers both power provided by the grid with a mix representative of the Southeastern USA as well as power provided solely based on renewable sources. Hydrogen production from biomass may be an attractive possibility as renewable sources would be utilized, which may have a positive impact on emissions using methods explored in [21].

Most hydrogen is transported, either for the entire distance or in part, through pipelines. For cases with low quantity requirements, transportation by truck is used [22]. Hydrogen is typically transported in (1) gaseous form or (2) liquid state. A super-insulated truck can transport up to $4,000 \mathrm{~kg}$ of hydrogen as a liquid [23], more than six times the quantity of a compressed gas trailer, allowing fewer deliveries and enabling more economical transportation over longer distances. Presently, France and Germany transport hydrogen by truck as far as $962 \mathrm{~km}$ [24].

Two possible production locations for hydrogen are considered in this study: (1) an onsite unit constructed at the refueling site and (2) a central location for delivery to refueling sites. Delivery in both gaseous and liquid forms is considered. The delivery distances were 110 miles for hydrogen produced from renewable sources and 800 miles for liquid or gaseous delivery from SMR [25]. The onsite options considered in this study include SMR, which requires a gas supply and electrolysis, which requires a high-power electrical supply.

\subsection{Hydrogen storage}

Onsite hydrogen storage usually employs compressed gas storage or storage as a liquid, with the method chosen primarily dependent on the quantities required, space requirements, cost and delivery frequency [26]. Adequate ventilation and leak detection are essential in a safe hydrogen system design. Pressure sensors and leak detectors, along with related warning systems, are necessary since hydrogen is an odorless and colorless gas. Flame detectors are also required as hydrogen burns nearly invisibly. These instruments required to handle hydrogen safely are well-developed technologies for stationary applications. Development of potential safety implementation for mobile hydrogen systems are underway [27].

Appropriate material selection for hydrogen pipes and storage tanks is also necessary because some material, including certain metals, can become brittle when exposed to hydrogen for long periods of time. Commercially available compressed gas tanks, 350 bar of pressure, have been used in other railway applications [28]. This study assumes that approximately $24 \mathrm{~kg} \quad(\sim 800 \mathrm{kWh})$ of hydrogen could be stored in one cubic meter at a weight of $320 \mathrm{~kg}$, based on a commercially available tank [29].

\section{Simulator and methodology}

The STS and WARPSTAR tools individually present challenges for quick evaluation of the benefits of various powertrains [6]. The STS tool facilitates infrastructural modeling and the physical characteristic modeling; however, it does not allow architectural and energy studies. WARPSTAR lacks functionality for estimating the power demand for a particular route. These issues are resolved through use of an Integrated Hybrid Train Simulator (IHyTS). This can be used by train system designers and rail operators for quick evaluation of powertrain configurations. The IHyTS outputs fuel consumption. The GREET $^{\circledR}$ model was used to estimate energy consumption as well as emissions of vehicle and fuel combinations considering the entire energy supply chain.

\subsection{Integrated hybrid train simulator}

IHyTS is based on two existing and well-regarded simulation tools developed by the University of Birmingham and the University of Warwick [6-10]. However, it has characteristics that fulfill gaps presented by the STS while retaining the simplicity of the parameter definition. This makes it easy to study the impacts, in terms of energy consumption, of changes to any of the main components of the powertrain. STS and WARPSTAR were developed using the same software environment, which simplifies the integration process. As shown in Fig. 2, STS provides the route power demand to WARPSTAR, which in turn evaluates the vehicle's energy consumption. IHyTS improves the capability and, most importantly, the calculation of a conventional Train Performance Simulation (TPS) tool for accurate analysis of more complex railway vehicle architectures. The simulator can model single or multiple locomotives.

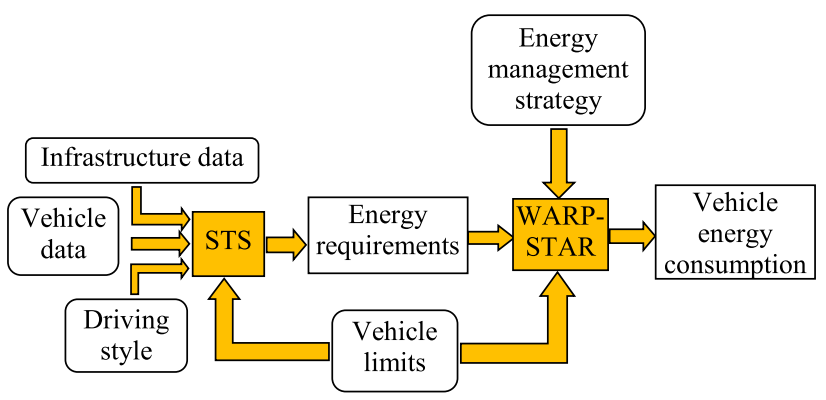

Fig. 2 Graphical representation of IHyTS developed to evaluate complex railway vehicle architectures 


\subsection{GREET $^{\circledR}$ model}

Typically, fuel life cycle analysis (LCA) is split into two parts: (a) pump-to-wheel (PTW) also called tank-to-wheel and (b) well-to-pump (WTP) or well-to-tank. The combination of PTW and WTP analyses is referred to as well-towheel (WTW) analysis. PTW analysis considers features of the powertrain technology and duty cycles and WTP analysis incorporates information about the fuel production and delivery. In this study, IHyTS performs the PTW component of the fuel LCA.

The GREET model [30, 31], developed by Argonne National Laboratories for automobiles, was adopted in this work to estimate the supply chain, energy, and emissions impacts. The model was adapted to account for railway vehicles in the WTP component of the fuel LCA. These modifications include considerations for the resource (or fuel) production and transportation to the point of use in the WTP energy consumption and emissions estimate.

\section{The Piedmont in North Carolina}

The Piedmont service corridor is a 173-mile $(\sim 278 \mathrm{~km})$ route, of which approximately half is single track and the remainder at least double track, with two terminal stations,

Table 1 List of station locations and dwell time for Piedmont service roundtrip journey

\begin{tabular}{lccl}
\hline Station & \multicolumn{2}{l}{ Distance of trip } & Dwell time (min) \\
\cline { 2 - 3 } & $(\mathrm{km})$ & $(\mathrm{miles})$ & \\
\hline Raleigh & 0 & 0 & 2 \\
Cary & 14 & 9 & 2 \\
Durham & 42 & 26 & 2 \\
Burlington & 97 & 60 & 1 \\
Greensboro & 132 & 82 & 2 \\
High Point & 154 & 96 & 1 \\
Salisbury & 210 & 131 & 1 \\
Kannapolis & 235 & 146 & 1 \\
Charlotte & 278 & 173 & 50 \\
Kannapolis & 321 & 200 & 1 \\
Salisbury & 346 & 215 & 1 \\
High Point & 402 & 250 & 1 \\
Greensboro & 424 & 264 & 2 \\
Burlington & 459 & 285 & 1 \\
Durham & 514 & 319 & 2 \\
Cary & 541 & 336 & 2 \\
Raleigh & 560 & 348 & 2 \\
\hline Stion in & 519 & &
\end{tabular}

Stations in bold are terminals
Raleigh and Charlotte, and seven intermediate passenger rail stations. A one-way trip (presented in Table 1), which includes nine total stops and the dwell time at each, takes the diesel-electric locomotive $190 \mathrm{~min}$ [32].

The altitude at Raleigh is $\sim 91 \mathrm{~m}$ which is depicted as the zero-starting point in Fig. 3, and the end point of the route is Charlotte $\sim 213 \mathrm{~m}$ which is shown by the midpoint of Fig. 3. The change in elevation between Raleigh and Charlotte is $\sim 122 \mathrm{~m}$. The route data including grades were provided by NCDOT. The maximum train speed along the route is $79 \mathrm{mph}(\sim 127 \mathrm{~km} / \mathrm{h})$, as limited by the line speed of $80 \mathrm{mph}$, and the average speed is $63 \mathrm{mph}$ $(\sim 100 \mathrm{~km} / \mathrm{h})$. Gradients have a significant impact on the resistance to motion encountered by the train and therefore significantly influence traction and braking requirements of the equipment operated over the route. The gradient profile for the Piedmont service, shown in Fig. 3, is provided by NCDOT as a percentage. The IHyTS integrates cumulatively, with respect to the discretized distance change, to obtain the change in altitude of the track. It should be noted that this change in altitude is measured for the track only and a terminal is used as the starting point. Figure 3 shows the grade in red on the left axis and the relative altitude in black on the right axis (Raleigh station altitude is referenced as zero).

The Piedmont service, which operates entirely within North Carolina, travels through many counties that were registered by the Environmental Protection Agency (EPA) for non-attainment of air quality standards in the past [33]. As a public entity, NCDOT desired to limit their impact on air quality from rail operations. To achieve that objective, the rail division has previously examined use of alternative fuels for railway motive power. These efforts included testing of biodiesel and blends of petro- and biodiesel, including B20 biodiesel, which demonstrated up to a $60 \%$ emissions reduction in carbon monoxide (CO), hydrocarbon (HC), and particulate matter with diameter less than $2.5 \mu \mathrm{m}$ (PM2.5). However, these fuels, tested in three inservice locomotives, had limited impact on nitrogen oxides $\left(\mathrm{NO}_{x}\right)$ [34]. Additionally, a blended after-treatment system (BATS) improved emissions from Tier $0+$ to Tier $3+$ with Tier 4 upgrades currently in progress [27]. Therefore, investigation of hydrogen as a potential fuel for NCDOT's rail operation complements previous efforts.

Currently, there are no hydrogen production locations in North Carolina. Therefore, transportation from out-of-state is required. Two possible production locations for hydrogen are considered in this study: (1) an onsite unit constructed at the refueling site and (2) a central location for transport to NCDOT facilities. 


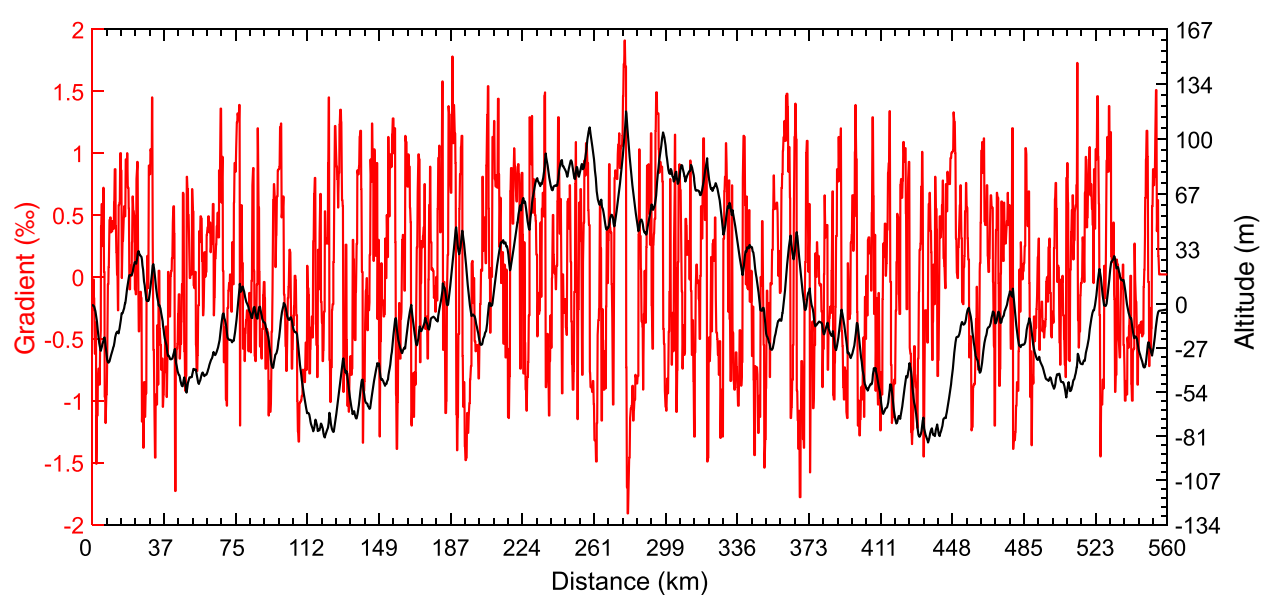

Fig. 3 Gradient and elevation change of the Piedmont route, starting in Raleigh

Table 2 Comparison of simulated and recorded data from Piedmont service operated by NCDOT

\begin{tabular}{llll}
\hline Parameter & Data & & Error \\
\cline { 2 - 3 } & Recorded & Simulated & $(\%)$ \\
\hline Journey time (min) & 187 & 190 & 1.58 \\
Fuel consumption (gal) & 640 & 650 & 1.54 \\
\hline
\end{tabular}

\section{IHyTS validation}

Journey time, speed profiles, and fuel consumption were provided by NCDOT. Accuracy of the IHyTS was evaluated using recorded data from a diesel-electric locomotive on the Piedmont service. The seven stops along the oneway journey are included in the simulator as well as the dwell time at each stop. The speed, journey time, and total diesel fuel consumption for a single trip were used for validation.

As shown in Table 2, fuel consumption resulting from the simulation is $\sim 640$ gal $(\sim 2,422.4 \mathrm{~L})$, which is close to the recorded value provided by the NCDOT, $\sim 650 \mathrm{gal}$ ( $\sim 2,460.25 \mathrm{~L})$. The fuel consumption mirrors the power demand for the required journey, and the diesel benchmark falls within the expected average fuel consumption.

NCDOT operates with positive train control which precludes extended periods of exceeding mandated track speed. The IHyST determines speed based on physical constraints provided by the user. This takes into account permissible acceleration and deceleration rates and other physical limitations, which are calculated and instituted into the controls of the train simulation. In the simulated case, the controls were set to operate the train as fast as allowable in line with infrastructure constraints and powertrain possibilities. The IHyTS speed profile is similar to the train speed data provided by NCDOT, as shown in Fig. 4. The differences between the simulated and recorded speeds lie within the boundaries of driving style variations. Recorded power data were not available to validate simulated power profiles across the powertrain, as illustrated in Figs. 11, 12 and 13. However, the recorded speed profile, journey time, and fuel consumption were provided by NCDOT and used to ensure simulation accuracy as shown in Table 2 and Fig. 4. Instrumentation of a locomotive to obtain power profiles across the powertrain is subject of future work to further corroborate these results.

\section{Case studies}

This feasibility study evaluates the WTW energy consumption and emissions.

\subsection{Powertrain configurations}

Four powertrain configurations were considered: (i) dieselelectric, (ii) fuel cell, (iii) hybrid fuel cell and (iv) plug-in hybrid fuel cell. The diesel-electric single locomotive, shown in Fig. 5, models the current NCDOT configuration and is used as a benchmark for this study. All of the cases presented here consider four powered axles on each locomotive. Additionally, a cab control unit (CCU) is considered for each; however, it is retrofitted in two of these cases.

The fuel cell single locomotive is shown in Fig. 6. Sufficient energy could be carried on-board the vehicle for one roundtrip before refueling, and recharging would be necessary. Four hybrid configurations are evaluated. Each hybrid fuel cell case explores a single locomotive and a 


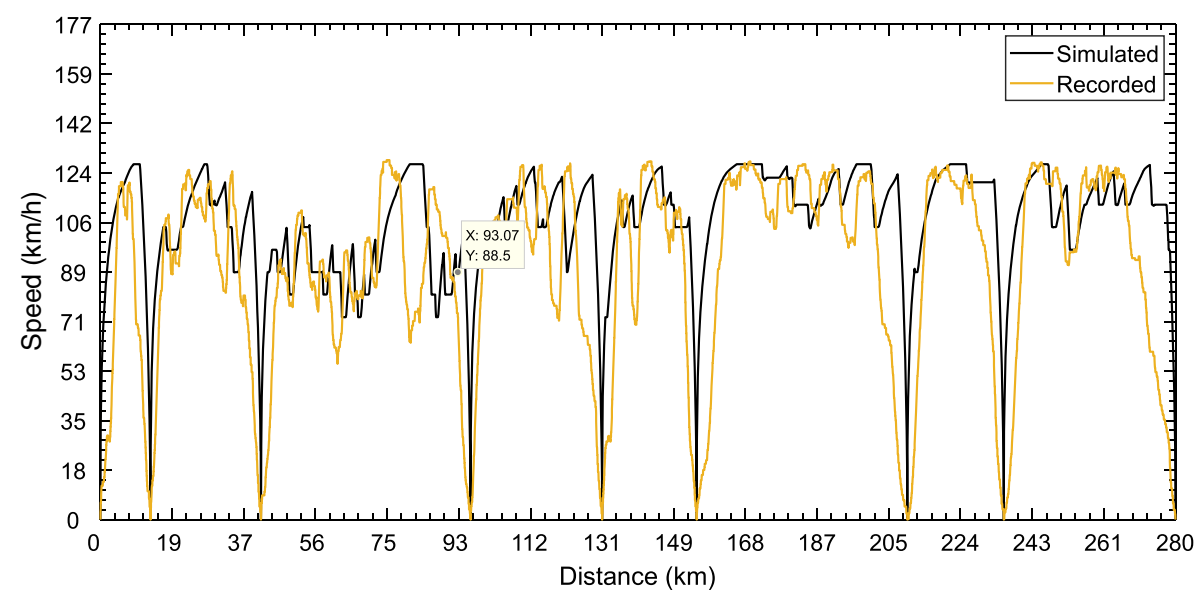

Fig. 4 Comparison of NCDOT Piedmont service recorded speed data and simulated speed with similar driver style

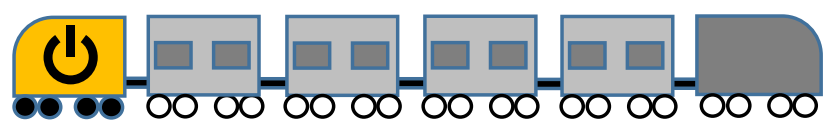

Fig. 5 Diesel-electric single locomotive

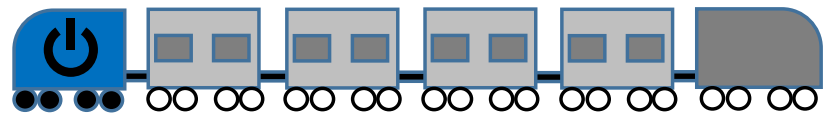

Fig. 6 Fuel cell single locomotive

double locomotive option, as shown in Figs. 7, 8, 9 and 10. Each hybrid uses the same battery type. The state of charge for the battery cells is also taken into consideration, and the battery limitations are employed to preserve battery life but still provide the required energy demand [21]. The battery state-of-charge requirement is constant in each case. It is assumed here that the plug-in hybrids are charged at the end of each one-way journey; therefore, the fuel cell is downsized in those cases. The double locomotive options provide more available space and allow a heavier powertrain as the components required for energy storage and power provision can be split between two motive power vehicles.

\subsection{Hydrogen sources}

Although hydrogen fuel cell technologies serve as zeroemission options in terms of vehicle operations, the

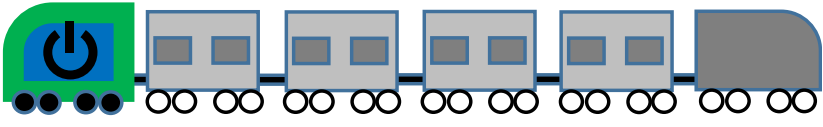

Fig. 7 Hybrid fuel cell single locomotive

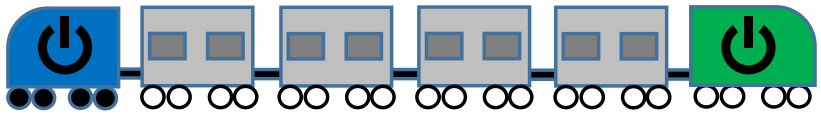

Fig. 8 Hybrid fuel cell double locomotive

hydrogen sources are included in this study in order to assess a more complete environmental impact for each vehicle. This study considers nine hydrogen production pathways that contribute to reduction in emissions:

- Onsite SMR

- Onsite electrolysis with electricity provided from the grid in North Carolina considering the representative production mix (SERC)

- Onsite electrolysis-100\% renewable energy

- Off-site production, liquid delivery SMR

- Off-site production, liquid delivery biomass

- Off-site production, gaseous delivery-electrolysis SERC

- Central production, liquid delivery-electrolysis SERC

- Off-site production, gaseous delivery-electrolysis$100 \%$ renewable energy 


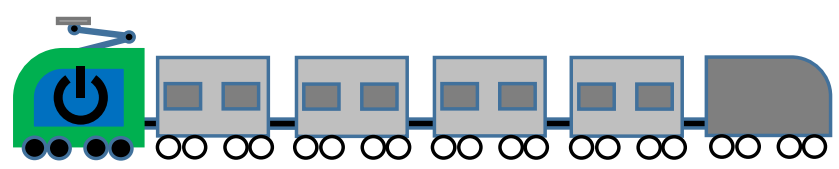

Fig. 9 Plug-in hybrid fuel cell single locomotive

- Off-site production, liquid delivery-electrolysis-100\% renewable energy with delivery distance considerations

\section{Results and analysis}

Feasibility of each configuration was assessed based on ability of the powertrain to provide the required power as well as space and weight constraints of the CCU resulting from the corridor infrastructure. The IHyTS evaluated a roundtrip journey between Raleigh to Charlotte for the fuel cell, hybrid fuel cell, and plug-in hybrid fuel cell configurations. The traction profile is identical for all three configurations, as it is based on the power demand.

For the non-hybrid option, the fuel cell system was dimensioned according to the power rating of the locomotive. As shown in Fig. 11a, the peak powerplant output is approximately $2.4 \mathrm{MW}$, similar to the benchmark diesel. The powerplant output provides the energy utilized over the entire course of the journey, as there is no battery system supporting the power demand. The powerplant output is able to provide the demand at the wheels as shown by input and power output profile, Fig. 11b. Though no dynamic braking energy storage is included with the powertrain configuration, the dynamic braking profile is included in Fig. 11b where the electrical energy would be dissipated in resistor grids as with conventional dieselelectric locomotives. Here, all the energy is derived from the hydrogen conversion.

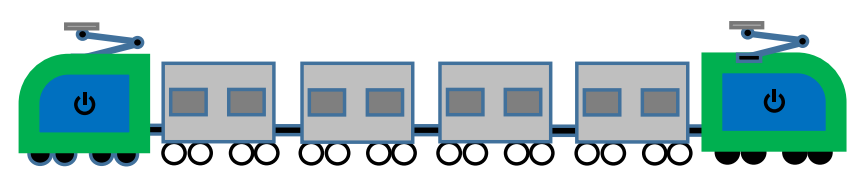

Fig. 10 Plug-in hybrid fuel cell double locomotive

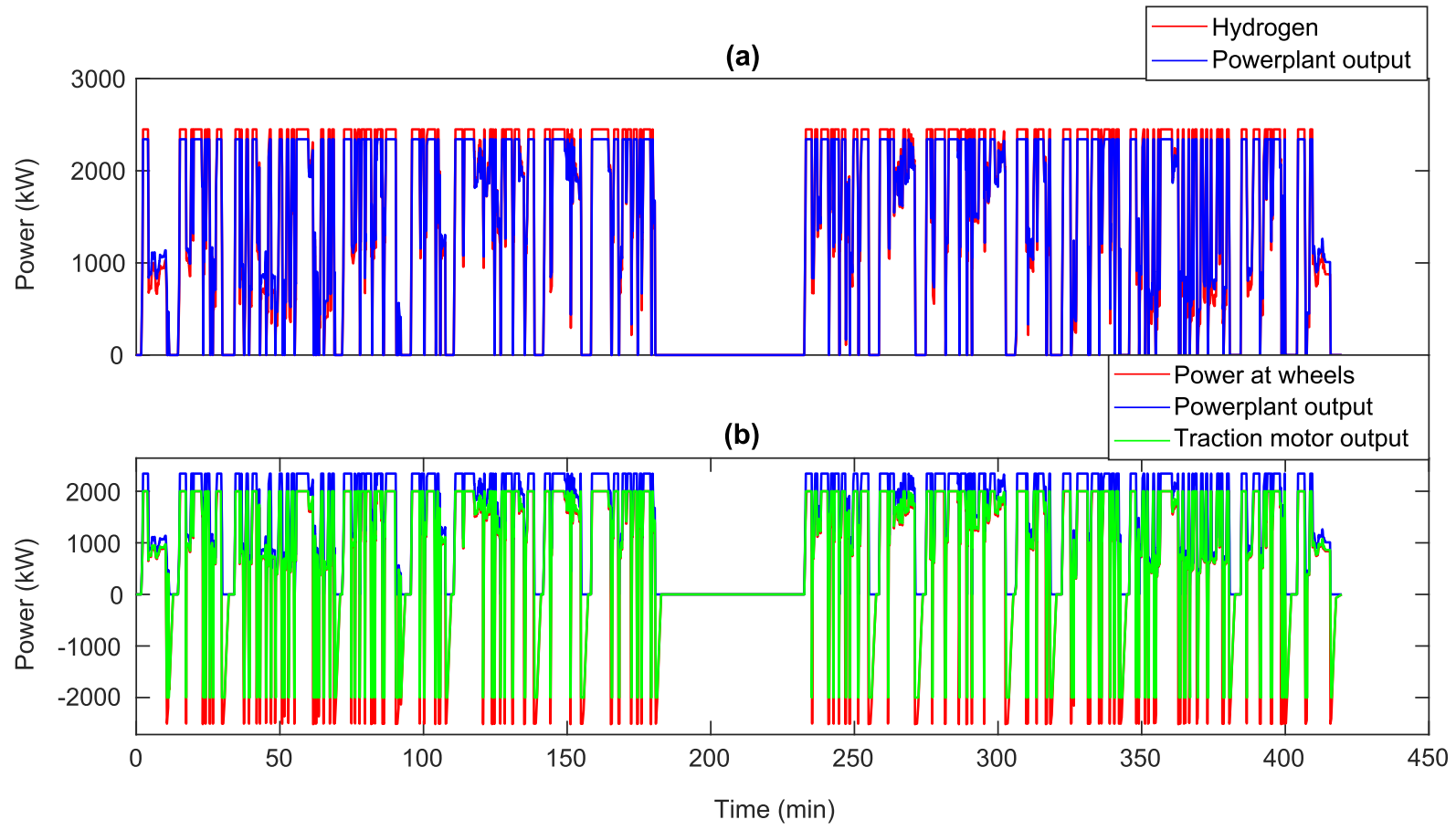

Fig. 11 Fuel cell non-hybrid power profile: a hydrogen powerplant $\mathrm{H}_{2}$ input and electrical output; b total power input and output at the DC bus 


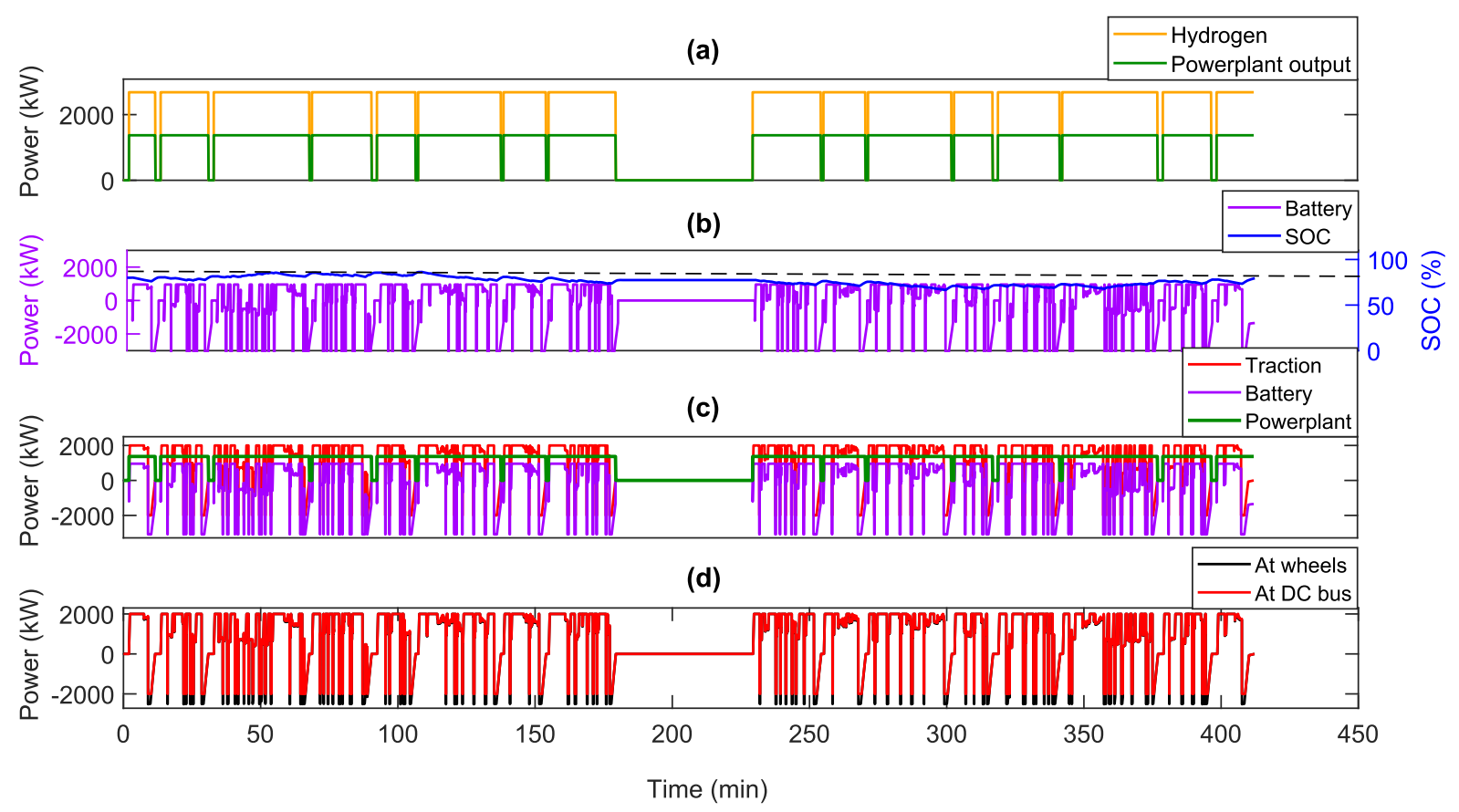

Fig. 12 Fuel cell hybrid (not plug-in) power profile: a fuel cell powerplant; b battery power output and state of charge; c power at DC bus; d traction power

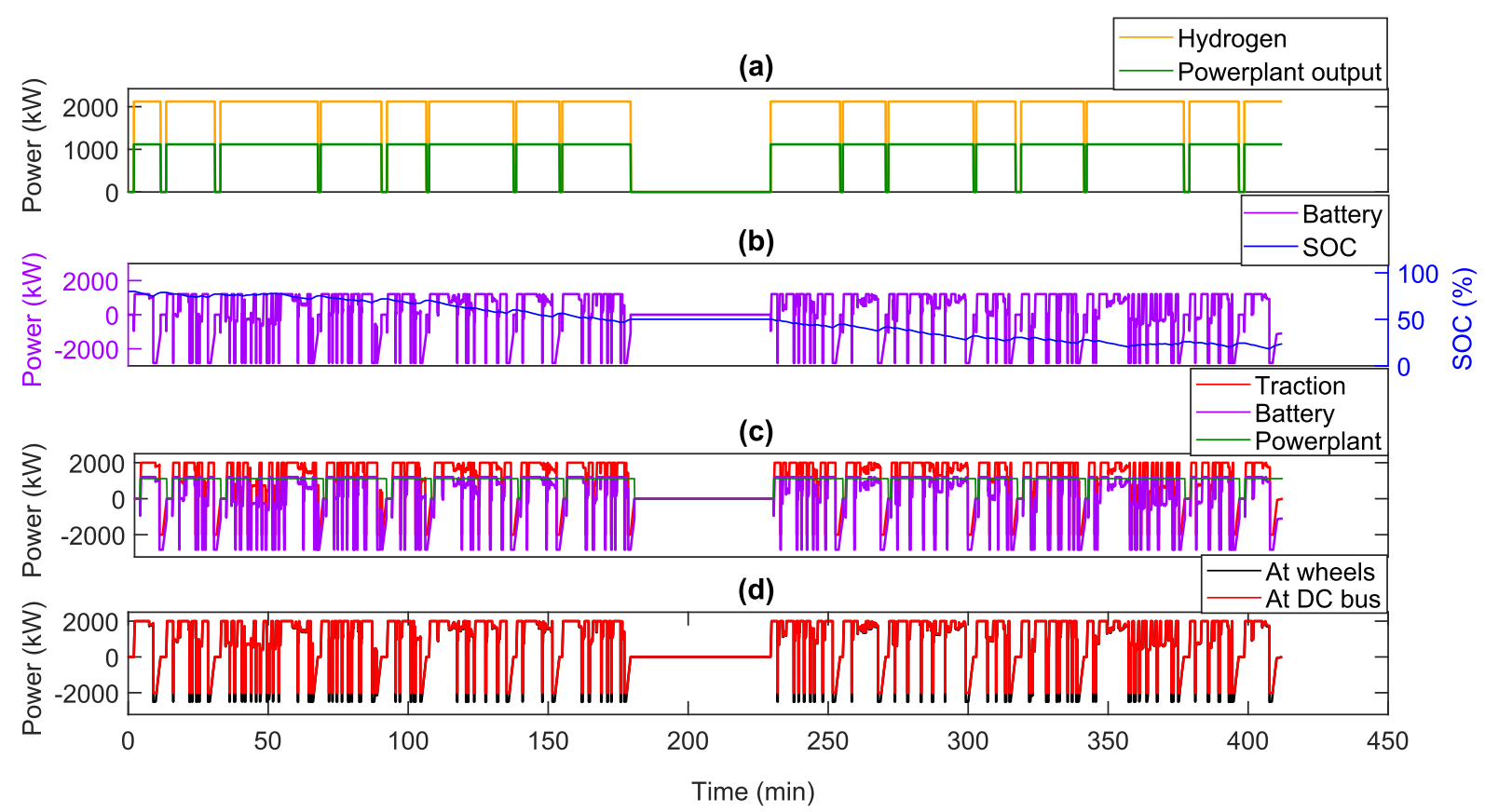

Fig. 13 Fuel cell hybrid plug-in power profile: a fuel cell powerplant; $\mathbf{b}$ battery power output and state of charge; $\mathbf{c}$ power at DC bus; $\mathbf{d}$ traction power 
Table 3 Feasibility of single locomotive fuel cell options

\begin{tabular}{|c|c|c|c|c|c|c|}
\hline \multirow[t]{2}{*}{ Configuration } & \multicolumn{3}{|c|}{ Powertrain volume $\left(\mathrm{m}^{3}\right)$} & \multicolumn{3}{|l|}{ Powertrain mass $(\mathrm{t})$} \\
\hline & Two walkways & One walkway & Feasibility & Same as locomotive & Higher limit & Feasibility \\
\hline Available in CCU & 41 & 52.5 & - & 41 & 48 & - \\
\hline Fuel cell & 34 & 34 & Yes & 15 & 15 & Yes \\
\hline Fuel cell hybrid & 49 & 49 & Yes & 47 & 47 & Yes \\
\hline Fuel cell hybrid plug-in & 45 & 45 & Yes & 46 & 46 & Yes \\
\hline Fuel cell hybrid downsized & 48 & 48 & Yes & 46 & 46 & Yes \\
\hline Fuel cell hybrid downsized plug-in & 44 & 44 & Yes & 44 & 44 & Yes \\
\hline
\end{tabular}

In the hybrid fuel cell locomotive, the fuel cell and onboard energy storage system supply the required power. The on-board energy storage system employed in this study was batteries. To supply the power demand, all the power sources, shown in Fig. 12c, are connected to a common DC bus. The nominal bus voltage for the system matches the traction motor requirements, as shown in Fig. 12d. Here, a power management system that regulates power flow shared between the fuel cell and the batteries is employed to ensure the system operates with high efficiency and good dynamic response. The power management system regulates the output power of the fuel cell, the charging current and voltage of the battery, and the output voltage of the power supply. The fuel cell is sized to ensure that the battery state of charge at the beginning and end of the journey are the same, as shown in Fig. 12b. Throughout the journey, the battery state of charge varies. The battery power is sized to match the difference in the instantaneous power demand and the average power demand. Considering battery life is greatly affected by the range of SOC, the SOC needs to be maintained between $40 \%$ and $80 \%$. Dissipation of the energy, which can be replenished during regenerative braking phases, reduces the demand on the fuel cell power plant. As shown in Fig. 12a, the fuel cell powerplant operates at $65 \%$ percent of its capacity thus reducing the hydrogen demand required. The fuel cells provide the average power, while the battery covers the instantaneous power difference.

For the plug-in hybrid fuel cell, the battery SOC is allowed to fall to $40 \%$ of the initial charge, as shown in Fig. 13b, reducing the required power from the power plant. As expected, the increased battery energy output reduced the powerplant output hence a reduction in the hydrogen required. The powerplant output is lowest for this configuration at $50 \%$ of its capacity, shown in Fig. 13a. The power at the DC bus, shown in Fig. 13d, is the sum of the hydrogen fuel cell and the battery output, shown in Fig. 13c.

The GREET model was employed after the fuel consumption was calculated from the simulation. The feasibility to carry the fuel required on-board was also a factor that was taken into account. Table 3 presented the space limitations and the required fuel fell within the space constraints. Volume estimation for each powertrain configuration was made using the hydrogen requirement from the IHyST results and the battery in the hybrid cases. The locomotive used in this study has $41 \mathrm{~m}^{3}$ available in the CCU. As shown in Table 3, the fuel cell configuration is feasible. The hybrid options are feasible with elimination of one walkway or other CCU volume expansion methods, such as raising the internal roofline to accommodate additional equipment while remaining within the loading gauge.

The impact of battery weight for the hybrid options is evident in Table 3. While the fuel cell configuration is a third of the weight of the current locomotive, all of the hybrid options are heavier yet lower than the upper limit, which is $48 \mathrm{t}$. The hybrid option requiring the least volume and having the lowest weight is the downsized plug-in hybrid fuel cell configuration. The plug-in hybrid, without downsizing, is the next best hybrid option considering volume and weight.

The impact on WTP energy consumption for the three configurations varies by hydrogen production pathway. The nine pathways taken into consideration were presented in Sect. 6.2. These pathways assume that the infrastructure is available, they also give an indication of alternative options in case one is not readily available. The plug-in hybrid fuel cell provides an energy reduction with seven of the nine pathways, as shown in Fig. 14. Onsite electrolysis using renewable energy has the highest WTW energy reduction for both hybrid options. The pathway offers a $37 \%$ reduction in fuel cell plug-in version and a $23 \%$ energy reduction with the non-plug-in version. However, this pathway does not make a difference in the fuel cell non-hybrid as the hydrogen used actually results in an energy penalty of $3 \%$.

The least favorable pathway is liquid delivery using electrolysis with electricity provided by the grid. The nonhybrid fuel cell results in a $110 \%$ energy penalty. 


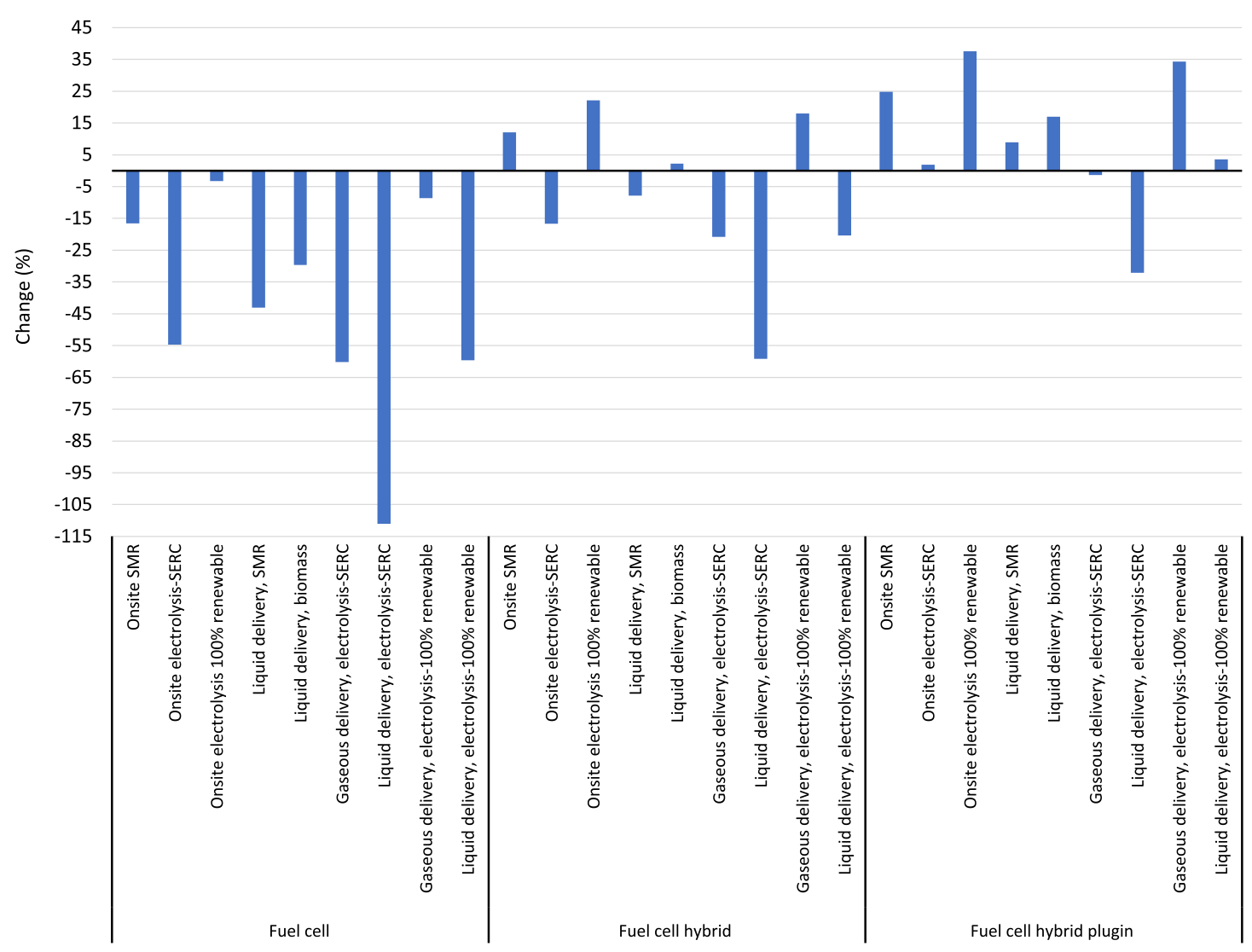

Fig. 14 Single locomotive fuel cell options WTW energy. Here, positive value denotes reduction

Liquefying hydrogen takes a lot of energy, and the penalty is compounded by the energy obtained from the grid. The plug-in version has a $33 \%$ penalty, which is better than the non-hybrid. This pathway is undesirable for any configuration. Using energy provided by the SERC grid results in unsustainable pathways for production of hydrogen. Additionally, the non-hybrid configuration should be avoided as it does not have any merits. Considering liquid delivery options, biomass is the best option as it has a better advantage for both hybrid configurations.

On-site SMR and all three of the renewable pathways provide net zero emissions for each fuel cell configuration, as shown in Fig. 15. These pathways assume all the energy is renewable; hence, the hydrogen usage does not play a role. This is the best option for emissions; however, it requires implementation of the infrastructure. Hydrogen provided by the SERC grid has the highest GHG impact, with liquid delivery for the non-hybrid option having $140 \%$ increase in emissions. The SERC grid mainly depends on gas and coal for electricity generation hence the high GHG emissions for the pathways dependent on the grid. Additionally, it is worth noting that these pathways also have a
WTW energy penalty. Liquid delivery biomass still has a net positive reduction, performing better for the plug-in version and non-plug-in with $60 \%$. It, however, reduces to $40 \%$ for the non-hybrid option as it relatively uses more hydrogen compared to the other two options. The plug-in version performs better in GHG emission for all the pathways as expected. However, if renewable energy sources are employed, there is flexibility in choosing the configuration desired if GHG reduction is the focus.

The double locomotive configurations follow the same pattern as the single locomotive configurations across the various hydrogen supply options. Overall, a hydrail option could be feasible and offers zero-emission operations with the potential to reduce WTW emissions depending on the hydrogen production pathway.

\section{Summary}

The energy impact and GHG emissions are presented for several fuel pathways and vehicle configurations. The technical feasibility was based on the ability of the 


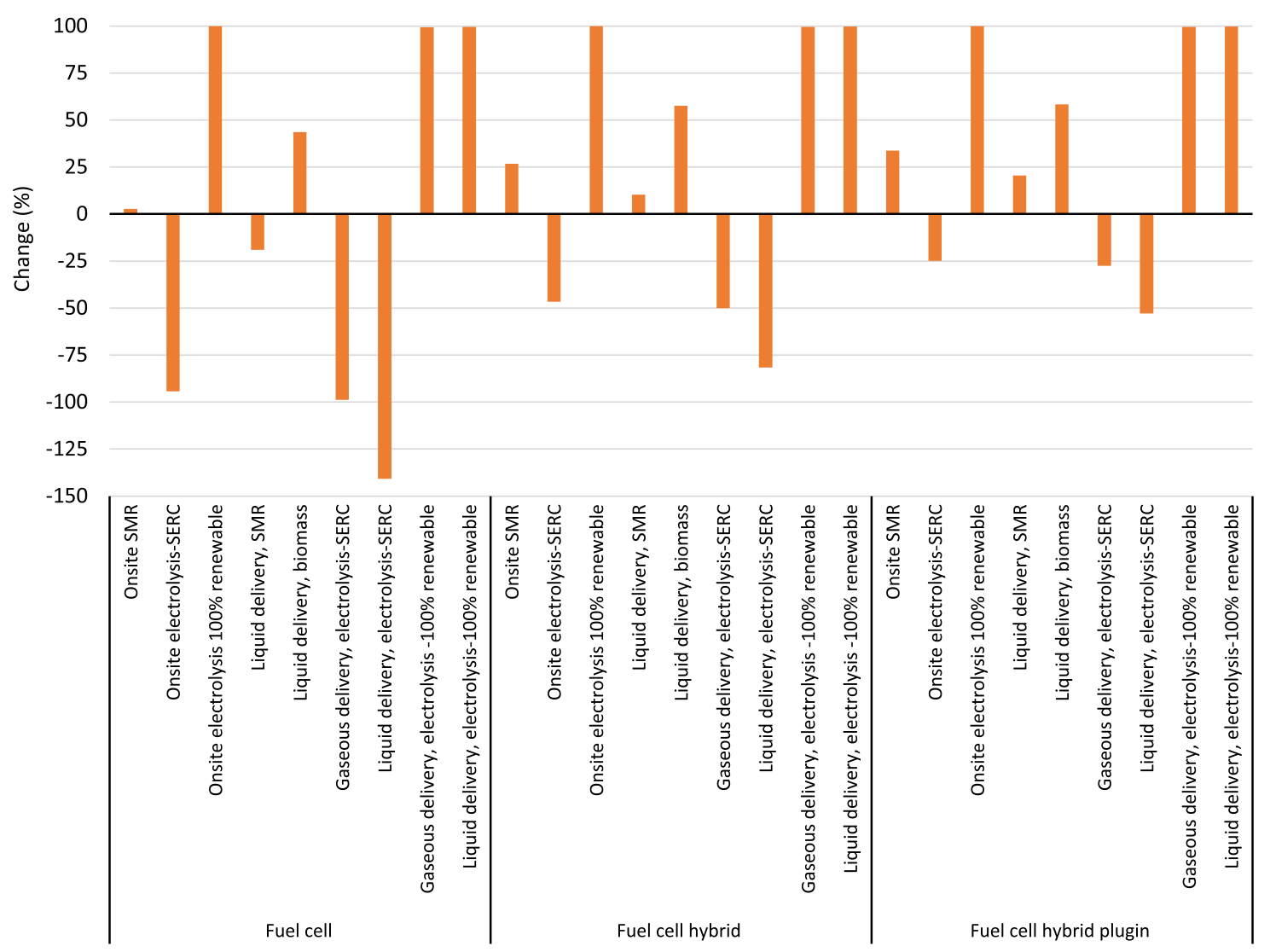

Fig. 15 Single locomotive fuel cell options WTW GHG. Here, positive value denotes reduction

powertrain to provide the required power and satisfaction of space constraints. Hydrail technology is deemed feasible for implementation on the Piedmont corridor. Sufficient power can be provided by either a fuel cell powertrain or a fuel cell hybrid powertrain to meet speed expectations and journey time. From this initial assessment, the two-locomotive fuel cell downsized hybrid plug-in option with four traction motors appears to be the most preferable for the Piedmont service, considering weight and volume requirements, refueling frequency, number of fuel cell systems and energy and emission reduction potential.

Outfitting a CCU with a new powertrain to create a locomotive is probably a cost-effective option; however, further investigation is required to evaluate cost in more detail. The space constraints were explored for the existing locomotives, and the volume of the desired fuel cells and storage systems was taken into consideration based on dimensions provided by the manufacturers. The volume available in a CCU could likely accommodate all required equipment if refueling after one roundtrip is possible; however, a more detailed design assessment is required. Hydrogen storage at 350 bar would be feasible, but pressure could be increased to allow installation with a smaller volume requirement, if necessary. Distributing the powertrain across two locomotives, one on each end of the train, would likely enable a refueling frequency after two roundtrips. A journey time improvement of approximately 10 min could be achieved if all eight axles of these locomotives would be powered; however, energy reduction compared to the diesel-electric would be lower than with other options, with a decrease of approximately $18 \%$ for the hybrid option and $28 \%$ for the plug-in version.

Acknowledgements This study was funded by the North Carolina Department of Transportation. Lynn Harris, formerly with North Carolina Department of Transportation, provided information that improved the precision of the modeling as well as useful feedback throughout the project. Dave Cook, from Rail Propulsion System, provided guidance regarding the current equipment based on his experience with previous North Carolina rail division projects. Various potential component and energy suppliers provided information that assisted with the project. The single train simulator utilized in this work is an evolution and combination of tools first developed at the Birmingham Center for Railway Research and Education and WMG at the University of Warwick. Iraklis Athanasios provided guidance with the Single Train Simulation software used for evaluation.

Open Access This article is licensed under a Creative Commons Attribution 4.0 International License, which permits use, sharing, 
adaptation, distribution and reproduction in any medium or format, as long as you give appropriate credit to the original author(s) and the source, provide a link to the Creative Commons licence, and indicate if changes were made. The images or other third party material in this article are included in the article's Creative Commons licence, unless indicated otherwise in a credit line to the material. If material is not included in the article's Creative Commons licence and your intended use is not permitted by statutory regulation or exceeds the permitted use, you will need to obtain permission directly from the copyright holder. To view a copy of this licence, visit http://creativecommons. org/licenses/by/4.0/.

\section{References}

1. Davis S, Boundy RG (2020) Transportation energy data book: 38 edition (No. ORNL/TM-2019/1333). Oak Ridge National Lab, Oak Ridge, TN

2. Sweeney J, Donnelly A, McElwain L, Jones M (2002) Climate change: indicators for Ireland (2000-LS-5.2.2-M1). Environmental Protection Agency, Wexford

3. Isaac RS (2020) Fuels and fuel technologies for powering 21st century passenger and freight rail: simulation-based case studies in a US context, Dissertation, University of California, Davis. https://escholarship.org/uc/item/3wt0n8tx

4. Hoffrichter A, Hillmansen S, Roberts C (2016) Conceptual propulsion system design for a hydrogen-powered regional train. IET Electr Syst Transp 6(2):56-66

5. Bocharnikov Y, Tobias A, Roberts C et al (2007) Optimal driving strategy for traction energy saving on DC suburban railways. IET Electr Power Appl 1:675-682

6. Lu S, Hillmansen S, Ho TK, Roberts C (2013) Single-train trajectory optimization. IEEE Trans Intell Transp Syst 14:743-750

7. Newsom G (2020) Executive Order N-79-20. Sacramento, CA, State of California. https://sd32.senate.ca.gov/sites/sd32.senate. ca.gov/files/pdf/executive_order_n-79-20_-_a_technologyneutral_approach_to_zero_emission_mobility_11_10_20.pdf. Accessed 15 Jun 2021

8. Berkeley Simulation Software (2021) What is RTC? http:// berkeleysimulation.com/rtc.php. Accessed 14 Feb 2021

9. Rail Management Consultants International GmbH (2021) RailSys ${ }^{\circledR}-$ My favorite software at work. https://www.rmcon-int.de/ railsys-en/. Accessed 14 Feb 2021

10. AREMA (2018) Manual for railway engineering: Chapter 16 Economics of railway engineering and operations. Lanham, MD

11. Hillmansen S, Roberts C (2007) Energy storage devices in hybrid railway vehicles: a kinematic analysis. Proc Inst Mech Eng Part F J Rail Rapid Transit 221(1):135-143

12. Walker A, McGordon A, Hannis G, Picarelli A et al (2006) A novel structure for comprehensive HEV powertrain modelling. In: 2006 IEEE vehicle power and propulsion conference, Windsor, UK, 6-8 Sept. 2006. IEEE, pp 1-5

13. Urgun-Demirtas M (2019) GREET model: the greenhouse gases, regulated emissions, and energy use in transportation model. Office of Energy Efficiency and Renewable Energy. https://www. energy.gov/eere/bioenergy/articles/greet-greenhouse-gasesregulated-emissions-and-energy-use-transportation. Accessed 14 Feb, 2021

14. Hexagon (2019) Composite type 4 high-pressure tanks for $\mathrm{CNG}$ light-duty vehicles. Lincoln, NE. https://cdn.hexagongroup.com/ uploads/2020/04/Brochure_CNG-Light-Duty-Vehicles.pdf. Accessed 14 Feb, 2021
15. IEA (2009) Transport, energy and CO2: moving toward sustainability. https://iea.blob.core.windows.net/assets/imports/ events/14/Fulton_IEA_Day.pdf . Accessed 20 Feb, 2021

16. Johnson Matthey (2017) Battery systems. Davis, CA. http://www. jmbatterysystems.com/technology/our-guide-to-batteries. Accessed 16 Feb, 2021

17. Harris WL (2020) Trains: exploring decarbonization options. Stanford Hydrogen Focus Group Decarbonizing Heavy Duty Transport. Stanford CA

18. IEA (2006) Hydrogen production and storage: R\&D priorities and gaps. Hydrogen Implementing Agreement. Paris, IEA. http:// www.iea.org/publications/freepublications/

19. Stiegel GJ, Ramezan M (2006) Hydrogen from coal gasification: an economical pathway to a sustainable energy future. Int J Coal Geol 65(3-4):173-190

20. IEA (2021) The future of hydrogen-analysis. https://www.iea. org/reports/the-future-of-hydrogen. Accessed $14 \mathrm{Feb}, 2021$

21. Meegahawatte D, Hillmansen S, Roberts C, Falco M, McGordon A, Jennings P (2010) Analysis of a fuel cell hybrid commuter railway vehicle. J Power Sources 195(23):7829-7837

22. Hoffrichter A, Little N, Foster S et al (2020) The Piedmont service: hydrogen fuel cell locomotive feasibility connect NCDOT business resources. https://connect.ncdot.gov/projects/research/ Pages/ProjDetails.aspx?ProjectID=2019-43. Accessed 30 Dec 2020

23. Harris L (2019) Plans for hydrail implementation on NCDOT's Piedmont passenger trains. In: 2019 TRB annual meeting, Washington, DC

24. Lahnaoui A, Wulf C, Heinrichs H, Dalmazzone D (2019) Optimizing hydrogen transportation system for mobility via compressed hydrogen trucks. Int J Hydrog Energy 44(35):19302-19312

25. Pacific Northwest National Laboratory (2021) Basic hydrogen properties chart: hydrogen tools. https://h2tools.org/tools. Accessed $14 \mathrm{Feb}, 2021$

26. Li Z, Pan X, Sun K, Zhou W, Gao D, Liu S, Ma J (2014) Development of safety standard for mobile hydrogen refueling facilities in China. Int J Hydrog Energy 39(25):13935-13939

27. Kent S, Isaac R, Little N, Hoffrichter A (2019) Low- or zeroemission multiple-unit feasibility study. San Bernardino, CA, 30 Dec 2019

28. Hoffrichter A (2013) Hydrogen as an energy carrier for railway traction. Dissertation, University of Birmingham

29. Gillette JL, Kolpa RL (2008) Overview of interstate hydrogen pipeline systems (No. ANL/EVS/TM/08-2). Argonne National Lab, Argonne, IL, US

30. Air Products and Chemicals Inc (2013) SmartFuel hydrogen supply options. Allentown, PA

31. Hexagon Lincoln (2017) Hydrogen storage and transportation systems. Lincoln, NE

32. NC By Train (2021) NCDOT. https://www.ncbytrain.org/ schedules/Pages/piedmont.aspx Accessed 14 Feb 2021

33. EPA (2020) North Carolina nonattainment/maintenance status for each county by year for all criteria pollutants, Green Book. https://www3.epa.gov/airquality/greenbook/anayo_nc.html. Accessed 14 Feb 2021

34. Frey HC, Graver BM, Hu J (2016) Locomotive biofuel studyrail yard and over the road measurements using portable emissions measurement system (No. DOT/FRA/ORD-16/04). Office of Research, Development, and Technology, US Department of Transportation, Federal Railroad Administration, Washington, DC 20590 